\title{
Cytogenetic Anomalies in Pediatric Leukemia Patients
}

\section{Çocukluk Çağı Lösemi Tanılı Hastalarda Sitogenetik Anomaliler}

\author{
$\underline{\text { Süreyya Bozkurt }}^{1}$, Şule Ünal ${ }^{2}$, Turan Bayhan ${ }^{3}$, Fatma Gümrük ${ }^{2}$, Mualla Çetin ${ }^{2}$ \\ ${ }^{1}$ İstinye Üniversitesi Tıp Fakültesi Tıbbi Biyoloji A.B.D., İstanbul, Türkiye \\ ${ }^{2}$ Hacettepe Üniversitesi Tıp Fakültesi, Çocuk Hematoloji Bölümü, Ankara,Türkiye \\ ${ }^{3}$ Dr.Abdurrahman Yurtaslan Onkoloji Hastanesi, Çocuk Onkoloji ve Hematoloji Kliniği, Ankara, Türkiye
}

Dergiye Ulaşma Tarihi: 18.03.2019 Dergiye Kabul Tarihi:22.07.2019 Doi: 10.5505/aot.2019.86648

ÖZET
GíRiş ve AMAÇ: Konvansiyonel sitogenetik analiz, çocukluk çağında görülen akut lenfoblastik lösemi (ALL)
ve akut myeloid lösemi (AML) hastalarında hem tanı hem de hastalık seyrinin izlenmesinde oldukça yol
göstericidir. Bazı kromozomal anomaliler spesifik olarak belirli lösemi alt gruplarında görülebilmektedir. Ayrıca
hastaların taşıdığ1 sayısal ve kromozomal anomalilerin bazıları iyi prognoz belirteci iken bazıları da kötü
prognoz belirteçleridir. Sunduğumuz bu çalış̧mada kromozomal anomali tespit edilmiş 10 AML ve 16 ALL
olmak üzere toplam 26 pediatrik lösemi hastasının sitogenetik analiz sonuçları ile hastaların klinik parametreleri
arasındaki korelasyon araştırıldı. YÖNTEM ve GEREÇLER: Hastalara ait konvansiyonel analizler, uyarılmamış kemik iliği örneklerinden, Giemsa-tripsin (GTG bantlama) yöntemi ile elde edilmiş metafaz kromozomlarının incelenmesi ile oluşturuldu.

BULGULAR: Hem AML hem de ALL hastalarında çeşitli yapısal ve sayısal anomaliler tespit edilmiştir. Bu anomaliler literatür ile uyumlu olup, hastaların lösemi tipleri ile de uyumluluk göstermiştir. Kompleks karyotipler AML hasta grubunda, ALL hasta grubundan daha fazla bulunmuştur. Ayrıca 1 ALL ve 2 AML tanılı hastada, nadir olarak görülen kromozomal anomaliler tespit edilmiştir.

TARTIŞMA ve SONUÇ: Günümüzde gelişmiş moleküler sitogenetik tekniklerin varlığına rağmen, konvansiyonel sitogenetik analiz halen oldukça önemli bir yere sahiptir.

Anahtar Kelimeler: Sitogenetik anomaliler, pediatrik lösemiler, pediatrik akut myeloid lösemi, pediatrik akut lenfoblastik lösemi

ABSTRACT
INTRODUCTION: Conventional cytogenetic analysis is very helpful in monitoring both the diagnosis and the
course of the disease in children with acute lymphoblastic leukemia (ALL) and acute myeloid leukemia (AML).
Some chromosomal abnormalities can be seen in specific subgroups of leukemia. In addition, some of the
structural and numerical chromosomal abnormalities carried by the patients are good prognosis indicators, while
others are bad prognosis indicators. In this study, we investigated the correlation between the cytogenetic
analysis results and clinical parameters of the 26 pediatric leukemia patients diagnosed with AML and ALL.
METHODS: Conventional cytogenetic analyzes of patients were made by examining metaphase chromosomes
obtained from non-induced bone marrow samples by Giemsa-trypsin (GTG banding) method.
RESULTS: Various structural and numerical anomalies were detected in both AML and ALL patients. These
abnormalities were compatible with the literature, and they were also compatible with the types of leukemia of
the patients. The complex karyotypes were found more in the AML patients group than in the ALL patients
group. In addition, three chromosomal anomalities which are seen very rarely were detected in 1 ALL and 2
AML patients.
DISCUSSION and CONCLUSION: Despite the presence of advanced molecular cytogenetic techniques,
conventional cytogenetic analysis still has an important value.
Keywords: Cytogenetic anomalies, pediatric leukemia, pediatric acut myeloid leukemia, Pediatric. acute
lenfoblastic leukemia.

Adress for correspondence: Dr. Öğr. Üyesi Süreyya Bozkurt, Maltepe Mah.324.sok. Beyaz Rezidans A Blok 21 Numara Zeytinburnu 34011 İstanbul - Türkiye 


\section{GíRiş}

Çocukluklarda görülen akut lenfoblastik lösemi (ALL) ve akut myeloid lösemi (AML) tüm çocukluk çağı kanserlerinin yaklaşık üçte birini oluşturmaktadır (1). $\mathrm{Bu}$ hastaların karyotiplerini belirlemek amacı ile yapılan konvansiyonel sitogenetik analizler hem tan 1 hem de hastalık seyrinin izlenmesinde önemli rol oynamaktadır. Çocukluk çağı ALL ve AML tanısı almış hastalarda, tanısal ve prognostik önemi olan çeşitli yapısal ve sayısal kromozomal anomaliler görülebilmektedir. Bu nedenle kromozomal anomalilerin doğru bir şekilde belirlenmesi oldukça önemlidir $(2,3)$. Çocukluk çağı B hücreli ALL'lerde en sıklıkla görülen sayisal anomali hiperdiploidi olup iyi prognoz belirtecidir. Kromozom sayısının 40'1n altında olduğu hipodiploidiler ise kötü prognoz işaretidir. ALL'de sayısal olduğu kadar çeşitli yapısal anomaliler de görülmektedir. Örneğin $\mathrm{t}(12 ; 21)(\mathrm{p} 13 ; \mathrm{q} 22)$ iyi prognoza işaret ederken, $\mathrm{t}(11 ; 19)(\mathrm{q} 23 ; \mathrm{p} 13.3)$ ve $\mathrm{t}(4 ; 11)(\mathrm{q} 21 ; \mathrm{q} 23)$ kötü prognoz göstergeleri olan kromozomal anomalilerdir $(4,6)$. ALL hastalarında olduğu gibi AML hastalarında da karyotipik analizler klinik öneme sahiptir. Örneğin $\mathrm{t}(8 ; 21)(\mathrm{q} 22 ; \mathrm{q} 22), \quad \mathrm{t}(15 ; 17)(\mathrm{q} 22 ; \mathrm{q} 21)$ ve $\operatorname{inv}(16)(\mathrm{p} 13 \mathrm{q} 22) \quad / \mathrm{t}(16 ; 16)(\mathrm{p} 13 ; \mathrm{q} 22)$ anomalileri sirasiyla AML-M2, AML-M3 ve AML-M4 alt tiplerinde görülmekte ve iyi prognoz belirteci olmakta iken del5q/Monozomi 5 ve del7/Monozomi 7 kötü prognoz belirteçleridir (7).

$\mathrm{Bu}$ çalışmada, karyotip analizi sonucu kromozomal anomali tespit edilen 10 AML ve 16 ALL olmak üzere toplam 26 pediatrik lösemi hastasının sitogenetik analiz sonuçları ile hastaların klinik parametreleri arasındaki korelasyon araştırıldı.

\section{GEREÇ ve YÖNTEM}

Çalışmaya 2011-2015 yılları arasında ALL ve AML tanısı almış ve çeşitli kromozomal anomaliler tespit edilmiş 26 çocuk hasta dahil edilmiştir. Tüm işlemler Helsinki beyanına uygun olarak yapıldı ve yerel etik kurul tarafindan onaylandı (Karar No: GO 13/21-07). $\mathrm{Bu}$ hastaların demografik özellikleri, sitogenetik ve immünfenotiplendirme sonuçlarının klinik ile korelasyonu ve bulunan kromozomal anomaliler tartışılmıştır. Hastaların konvansiyonel sitogenetik analizleri, hastalara ait 24 saatlik uyarılmamış kemik iliği örneklerinden elde edilen metafaz kromozomlarının incelenmesi ile gerçekleştirildi. Yöntemde önce, alınan kemik iliği örnekleri üridin ve fluorouridin eklenerek $37{ }^{0} \mathrm{C}^{\prime}$ lik etüve kaldırıldı. Ertesi gün timidin eklenerek 24 saatlik senkronize kültür elde edildi. Ardından kolşemid (0.05 g / mL) yarım saat süreyle kültüre eklendi. Daha sonra hücreler 30 dakika hipotonik solüsyonu $(0.075$ M KCI) içinde inkübe edildi. İnkübasyon sonrası hücreler Carnoy solüsyonuyla (3 kısım metanol/ $1 \mathrm{k} 1 \mathrm{sim}$ buzlu asetik asit) sabitlendi. Cam üzerine alınan örnekler tripsin ile muamele edilerek, ardından Giemsa ile boyandı (GTG bantlama). Analize hazır hale getirilen metafaz kromozomları görüntü analiz sisteminde (Metasistem/Almanya) incelendi. Her bir hasta için 20 metafaz analiz edilerek "2013 Uluslararas1 İnsan Sitogenetik İsimlendirme Sistemi”" (ISCN)'ne göre karyotipler oluşturuldu (8).

\section{BULGULAR}

Çalışmaya karyotip analizinde anomali saptanan ALL tanısı almış 16 çocuk hasta ile AML tanılı 10 çocuk hasta dahil edilmiştir.

\section{Akut lenfoblastik lösemi grubu}

ALL hastalarının özellikleri Tablo 1' de sunulmuştur. Hastaların üçü kız (\%18.7) ve 13’ü (\%81.3) erkek idi. Hastaların en küçüğü tanı sırasında 7 aylık, en büyüğü 11 yaş 5 aylık olmak üzere ortanca yaş 4 yil olarak bulundu. Hastaların tanı sırasında en düşük beyaz küre sayıs1 $1800 / \mathrm{mm}^{3}$ ve en yüksek beyaz küre sayıs1 $202.400 / \mathrm{mm}^{3}$ olmak üzere, ortalama sayı $37.618 \mathrm{~mm}^{3}$ bulundu. Onaltı hastanın ikisinde (\%12.5) merkezi sinir sistemi tutulumu tespit edildi. Yapılan immünfenotiplendirmeye göre, 15 hastaya B-hücre ALL, bir hastaya da Thücre ALL tanis1 konuldu. Hastalara StJudeTotalXVmodifiye protokolü verildi. Hastaların yedisi düşük risk grubunda, sekizi standart risk grubunda, bir hasta ise yüksek risk grubunda değerlendirildi.

Yapılan karyotip analizleri sonucu ALL hastalarında saptanan sitogenetik anomaliler Tablo 2'de sunulmuştur. Onaltı hastanın dördünde hiperdiploidkaryotip bulundu (Tablo 2: 1, 7, 12 ve 14 no'lu hastalar). $\mathrm{Bu}$ karyotiplerde, 2 ve 16. 
kromozomlar dışında diğer tüm otozomal ve cinsiyet kromozomlarının trizomi ve tetrazomileri tespit edildi. Beş hastada (Tablo 2: 2, 3, 6, 9 ve 13 no'lu hastalar) kompleks karyotip belirlendi. 7 hastada ise (Tablo 2: 4, 5 , $8,10,11,15,16$ no'lu hastalar) çeşitli sayısal ve yapisal anomaliler tespit edildi. Hiperdiploidi tespit edilen bu 4 hastanın 3'ünde (Tablo 2: 1, 7 ve 14 no'lu hastalar) hiperdiploidi hastalarm geliş anında tespit edilirken, 1 hastada (Tablo 2: 12 no'lu hasta) 2. relaps sirasinda tespit edildi. Bu hastaların 2-6 ay sonrasında kemik iliği örneklerinden tekrar edilen sitogenetik analizlerinde tüm hastalarda normal kromozom kuruluşu tespit edildi. Düşük risk grubu içinde değerlendirilen ve relaps gözlenmeyen hiperdiploidkaryotipe sahip 2 hasta (Tablo 2: 1 ve 7 no'lu hastalar) izlemde ve hayatta iken, yüksek risk grubunda olan ve 2.kez relaps olan hiperdiploidkaryotipli hasta (Tablo 2: 12 nolu hasta) ve standart risk grubunda olan ve relaps1 olmayan bir diğer hiperdiploidiye sahip hasta (Tablo 2: 14 no'lu hasta) kaybedildi. Kompleks karyotip tespit edilen 5 hastanın ise 4'ü hayatta olup, yalnız karyotipinde $\mathrm{t}(8 ; 14)(\mathrm{q} 24 ; \mathrm{q} 32)$, dup(1q) ve trizomi 13 tespit edilen hasta kaybedilmiştir. Kompleks karyotipe sahip ve hayatta olan 4 hasta immünfenotiplendirmeye göre pre-B ALL iken, $\mathrm{t}(8 ; 14)$ 'e sahip hasta CALLA negatif $\mathrm{B}$ hücreli ALL'dir. ALL hasta grubunda iki hastada (Tablo 2: 10 ve 15 no'lu hastalar), bugüne kadar çoğunlukla AML ve MDS hasta grubunda görülmüş olan del7q, monozomi 7 ve trizomi 19 tespit edildi. del(7)(q31q36)'nın tespit edildiği hastada (Tablo 2'de 10 no'lu hasta) bu anomali hastanın gelişinin 48 . Haftası tespit edilmiştir. Hasta düşük risk grubunda değerlendirilmiş olup hala izlemde ve sağdır. Monozomi 7 ve trizomi 19'un tespit edildiği hastada ise (Tablo 2'de 15 no'lu hasta) bu sayısal anomaliler hastanın kemik iliği nakli sonras1 relapsin görüldüğü 1 . ayda tespit edilmiştir ve sonrasında hasta kaybedilmiştir.

\section{Akut myeloid lösemi grubu}

Çalışmaya dahil edilen AML tanısı almış 10 hastanın özellikleri ise Tablo 3 , de sunulmuştur. Hastaların beşi kız $(\% 50)$, beşi erkek olup (\%50), tanı anında ortalama beyaz küre sayısı $36.840 \mathrm{~mm}^{3}$ bulundu. Ortanca yaş 7 y1l idi. On hastanın ikisinde (\%20) tanı anında merkezi sinir sistemi tutulumu tespit edildi.
AML hastalarının karyotipleri Tablo 4' de sunulmuştur. Buna göre 10 hastanın yedisinde (\%70) kompleks karyotip bulundu (Tablo 4: 14, 6, 8, 9 no'lu hastalar). Bu kompleks karyotiplerde, 1, 22, 3, 8 ve 4. kromozomların kısa kollarında delesyon, $\operatorname{der}(10), \operatorname{der}(6)$, $\operatorname{der}(2), \operatorname{der}(1)$ ve $\operatorname{der}(17), 14,22,19$ ve 7. kromozomların monozomisi, 8,19 ve 2 . kromozomların trizomisi ve marker kromozomlar tespit edildi. Üç hastada ise (Tablo 4: 5, 7 ve 10 no'lu hastalar) farklı yapisal ve sayisal anomaliler bulundu. Toplam 10 AML tanılı hastanın 4 tanesi hayatta olup, 1 hasta izlem dışıdır. 5 hasta ise kaybedildi ve bu hastaların dört tanesi kompleks karyotipe sahipti.

\section{TARTIŞMA}

Çocukluk çağı ALL hastalarının tedavisinde son yıllarda büyük ilerlemeler kaydedilmiştir ve 5 yıllık să kalım \%90'lar seviyesine ulaşmış durumdadır. Ancak hastaların bir kısmı tedaviye dirençli olabilmekte veya tedavi sonrası hastalık tekrar edebilmektedir (1). ALL hastalarının sahip olduğu kromozomal anomalilerin etkilediği genler, hastalık oluşumunda rol almasının yanı sıra, tedaviye dirençte ve hastalığın tekrar etmesinde de etkili olabilmektedir. $\mathrm{Bu}$ nedenle bu kromozomal anomalilerin prognostik değeri bulunmaktadır. Bizim çalışmamızda 16 ALL tanılı hastanın 4'ünde yüksek hiperdiploidkaryotip tespit edilmiştir. Yüksek hiperdiploidkaryotipler (kromozom sayıs1 51-67 arası) çocukluk çağ1 B-hücreli ALL'lerde en siklıkla (\%30) görülen sayısal anomalilerdir ve iyi prognoz belirteçleri olarak kabul edilirler. Hiperdiploidkaryotiplerde siklıkla X, 4, 6,10, $14,17,18$ ve 21 . kromozomların trizomileri ve tetrazomileri görülmektedir (9). Bizim çalışmamızda ise yüksek hiperdiploidi tespit ettiğimiz hastaların karyotiplerinde 2 ve 16 . kromozomlar haricinde $\mathrm{X}$ kromozomu ve diğer otozomal kromozomların trizomileri ve tetrazomileri bulunmuştur. Hastaların tümünde ortak olarak $6,14,15$ ve 21 . kromozomların trizomi ve tetrazomileri saptanmıştır. Araştırıcılar hiperdiploidkaryotipte özellikle trizomi 4 ve trizomi 10 birlikteliğinin düşük relaps ve daha iyi prognoz belirteci olduğunu bildirmektedirler $(10,11)$. Bizim çalışmamızda trizomi 4 ve trizomi 10 birlikteliği 2 hastada tespit edildi (Tablo 2: 7 ve 14 no'lu hastalar). 
Her iki hasta da relaps görülmedi ancak hastalardan biri (14 no'lu hasta) sepsis nedeni ile kaybedildi.

Çalışmaya alınan 16 ALL hastasının beşinde kompleks karyotip tespit edildi (Tablo 2: 2,3,6,9 ve 13 no'lu hastalar). Bu hastalarda $6 \mathrm{q}, 9 \mathrm{p}, 12 \mathrm{p}$ delesyonları, derive 14 , derive16, derive 18 , derive 20,20 ve 21 .kromozomlarm monozomisi, marker kromozomlar, $\mathrm{t}(8 ; 14)(\mathrm{q} 24 ; \mathrm{q} 32)$, dup(1q) ve trizomi13 tespit edildi. Kompleks karyotip yani 3 veya daha fazla kromozomal anomali bulunmas1, ALL hastalarında kötü prognoz belirteci olarak sayılmakta ve 5 yıllık hayatta kalım \%20-25 olarak belirtilmektedir. Literatürde $\mathrm{t}(8 ; 14)(\mathrm{q} 24 ; \mathrm{q} 32)$ 'ninadölesanlardadaha yaygın olarak görüldüğü ve kötü prognoz belirteci olduğu belirtilmektedir (12). Bizim $\mathrm{t}(8 ; 14)$ tespit ettiğimiz hasta da 14 yaşında olup, çalışmaya dahil edilen 16 ALL hastasından relaps olup kaybedilen 3 hastadan biridir. $\mathrm{Bu}$ hastanın taşıdığı anomali ve prognoz ilişkisi literatürü destekler niteliktedir.

Çalışmaya dahil edilen 16 ALL hastasının ikisinde $\mathrm{t}(4 ; 11)(\mathrm{q} 21 ; \mathrm{q} 23)$ tespit edildi. $\mathrm{Bu}$ translokasyon tipik olarak CD10 (CALLA negatif) immünfenotiplendirmeye sahip hastalarda görülmektedir ve bizim bu anomaliyi tespit ettiğimiz 2 hasta da literatüre uygun şekilde CD10 (CALLA negatif) idi. Bazı sitogenetik anomaliler özellikle bazı yaş gruplarında görülebilmektedir. $\mathrm{t}(4 ; 11)(\mathrm{q} 21 ; \mathrm{q} 23)$ translokasyonunun da dahil olduğu 11.kromozomun q23 bölgesini içeren MLL geni yeniden düzenlenmeleri 1 yaşa kadar olan bebeklerde daha fazla görülmektedir (13). Bizim $\mathrm{t}(4 ; 11)$ tespit ettiğimiz 2 hastadan biri 4 yaşında iken diğeri 7 aylık bir bebek hasta idi (Tablo 2: sirasiyla 8 ve16 no'lu hastalar). Bu hastaların ikisi de standart risk grubunda olup relaps izlenmemiştir ve her iki hasta da hayattadır.

Bir ALL tanilı hastada (Tablo 2: 11 no'lu hasta) kırılma noktalarını kromozom kalitesi sebebi ile tam tespit edemediğimiz $t(10 ; 14)$ belirlendi. Bu T-hücreli ALL'ye spesifik bir anomalidir (13) ve bizim hasta grubumuzda da bu translokasyon, çalışmaya dahil edilen 16 ALL hastasının içinde, T-hücreli ALL tanıs1 alan tek bir hastada tespit edilmiştir.

Bir hastada da (Tablo 2: 4 no'lu hasta) analiz edilen metafazların tümünde $\mathrm{t}(7 ; 9)(\mathrm{p} 15 ; \mathrm{p} 22)$ ve del(9)(p12p24) bulundu . $\mathrm{Bu}$ translokasyon bu kırılma noktaları arasında, araştırılan veri tabanlarına göre bugüne kadar yalnız bir ALL tanılı çocuk hastada rapor edilmiştir. Bizim hastamız $\mathrm{t}(7 ; 9)(\mathrm{p} 15 ; \mathrm{p} 22)$ 'un tespit edildiği literatürdeki ikinci ALL olgusudur.

AML hasta grubuna bakıldığında ise 10 hastanın 7'sinde kompleks karyotip tespit edildiği görülmektedir (\%70) (Tablo 4: 1,2,3,4,6,8,9 no'lu hastalar). Kompleks karyotipe sahip AML ve ALL hastalarının sayısı kıyaslandığında, AML hastalarının, ALL hastalarına kıyasla daha çok kompleks karyotipe sahip olduğu bulunmuştur. Kompleks karyotipe sahip AML hastalarında, 7, 14 ve 19.kromozomların klonal kaybı göze çarpmaktadır. Ayrıca iki hastada, AML olgularının \%10-15'inde görülen trizomi 8 bulunmuştur (Tablo 4: 7 ve 8 no'lu hasta). Trizomi 8 her iki hastada da geliş anında değil, bir hastada 1. ayda, diğerinde de relaps anında tespit edilmiştir. Her iki hasta da diğer hastalardan daha fazla beyaz küre sayısına sahipti ve merkezi sinir sistemi tutulumu vard1. Hastalardan birinde (Tablo 4'de 7 no'lu hasta) trizomi 8'e del(13)(q14q22) eşlik etmekte idi. Delesyonlar hematolojik malignansilerde en sıklıkla karşımıza çıkan anomalilerdir ve del(13)(q14q22)'da myeloidmalignansilerde nispeten yaygın olarak görülür.13q14'de Retinoblastoma (RB) tümör baskılayıcı geni yerleşik olarak bulunmaktadır. RB geninin yapısal anomalileri özellikle de AML'nin M4 ve M5 alt gruplarında görülmektedir. 13q14 bölgesinde oluşan delesyon RB proteininin ifade edilmemesine yol açmaktadır. RB gen ifadesinin normal olduğu ve RB gen ifadesinin azaldığı hastalarda hayatta kalım açısından yapılan kıyaslama çalışmalarında, düşük RB ifadesinin negatif bir prognostik belirteç olduğu belirtilmektedir (14). Bizim olgumuzda del(13)(q14q22) trizomi 8 ile birlikte analiz edilen 20 metafaz da da tespit edildi, hasta literatüre uyumlu şekilde AML-M4 idi ve 6.ayda relaps sonrası kaybedildi.

Bir diğer hastada (Tablo 4'de 2 no'lu hasta) bulduğumuz del(1)(q32q44), araştırılan veri tabanlarına göre bugüne kadar sadece 8 hematolojik malignansili olguda tespit edilmiştir. Bu 8 olgudan 2 tanesi AML tanısı almış (AML-M1 ve AML-M3) erişkin hastalara aittir (14). Bizim hastamız AML-M5 idi ve bu anomali hastanın geliş ya da relaps anında değil 4. ayında tespit edildi. Relaps olan hasta kemik iliği nakli sonrası kaybedildi. 
Bizim hastamız bugüne kadar del(1)(q32q44) anomalisinin tespit edildiği 3. AML olgusu olup, çocuk hastada bu anomalinin bulunduğu ilk olgudur.

Sonuç olarak çocukluk çağı akut lösemilerde görülen sitogenetik anomaliler, hem prognozun değerlendirilmesi hem de tedavinin belirlenmesi açısından klinik öneme sahiptir. Kromozomal anomalilerin ayrıntılı bir şekilde belirlenmesi hastalıkların oluşum mekanizmalarının aydınlatılması yönünden de büyük önem taşımaktadır. Hastaların genetik patolojilerini moleküler düzeyde ortaya koyabilen gelişmiş moleküler sitogenetik teknikler bulunmasına rağmen klasik karyotip analiz halen çok önemli bir yere sahiptir.

Çıkar Çatışması: Yok

Tablo 1: ALL hastalarının klinik özellikleri

\begin{tabular}{|c|c|c|c|c|c|c|c|c|}
\hline $\begin{array}{l}\text { Hasta } \\
\text { No }\end{array}$ & Yaș & Cinsiyet & Tanı & $\begin{array}{l}\text { Flow } \\
\text { Tiplendirme }\end{array}$ & $\begin{array}{l}\text { Geliș } \\
\text { Beyaz } \\
\text { Kïre } \\
(/ \mathrm{mm} 3)\end{array}$ & $\begin{array}{l}\text { Sitogenetik } \\
\text { anormallik hangi } \\
\text { safhada; } \\
\text { geliş/relaps }\end{array}$ & $\begin{array}{l}\text { Bos } \\
\text { değerlendirme }\end{array}$ & Risk \\
\hline 1 & $\begin{array}{l}6,5 \\
\mathrm{y} 11\end{array}$ & $E$ & $\mathrm{ALL}$ & $\begin{array}{l}\text { pre B hücreli } \\
\text { CD33 + }\end{array}$ & 21700 & geliș & Tutulum yok & Düşïk \\
\hline 2 & $\begin{array}{l}4 \text { y1l } \\
3 \text { ay }\end{array}$ & $E$ & ALL & pre B hücreli & 16000 & geliş & Tutulum yok & düşüik \\
\hline 3 & $\begin{array}{l}2 \text { y1l } \\
10 \\
\text { ay }\end{array}$ & $\mathrm{K}$ & ALL & pre B hücreli & 47600 & geliş & Tutulum yok & düşüik \\
\hline 4 & $\begin{array}{l}1.5 \\
\mathrm{y} 11\end{array}$ & $E$ & ALL & pre B hücreli & 136400 & geliş̧ & Tutulum yok & standart \\
\hline 5 & $4 \mathrm{y} 11$ & $E$ & ALL & $\begin{array}{l}\text { pre B hücreli + } \\
\text { CD33 + CD13 + }\end{array}$ & 11700 & geliş & Tutulum yok & düşüik \\
\hline 6 & $5 \mathrm{y} 11$ & $E$ & ALL & $\begin{array}{l}\text { pre B hücreli + } \\
\text { CD33 + CD13 + }\end{array}$ & 3000 & geliş & Tutulum yok & düşüik \\
\hline 7 & $6 \mathrm{y} 1 \mathrm{l}$ & $\mathrm{E}$ & ALL & $\begin{array}{l}\text { pre B hücreli } \\
\text { CD13 + }\end{array}$ & 5400 & geliş̧ & Tutulum yok & düşüik \\
\hline 8 & $4 \mathrm{y} 1 \mathrm{l}$ & $\mathrm{E}$ & ALL & $\begin{array}{l}\text { CALLA negatif } \\
\text { B hücreli }\end{array}$ & 23100 & geliş & Tutulum yok & standart \\
\hline 9 & $\begin{array}{l}2.8 \\
\mathrm{y} 1 \mathrm{l}\end{array}$ & $\mathrm{K}$ & ALL & Pre B hücreli & 25600 & 7.hafta & travmatik & standart \\
\hline 10 & 4 yil & $\mathrm{E}$ & ALL & Pre B hücreli & 4400 & 48.hafta & Tutulum yok & düşükk \\
\hline 11 & $\begin{array}{l}1.6 \\
\mathrm{y} 11\end{array}$ & $\mathrm{E}$ & $\mathrm{ALL}$ & T hücreli & 91300 & geliş & travmatik & standart \\
\hline 12 & $\begin{array}{l}3.5 \\
\mathrm{y} 11\end{array}$ & $E$ & ALL & Relaps ALL & 3200 & 2.relapsta & Tutulum yok & yüksek \\
\hline 13 & $\begin{array}{l}14 \\
\mathrm{y} 11\end{array}$ & $E$ & ALL & $\begin{array}{l}\text { CALLA negatif } \\
\text { B hücreli }\end{array}$ & 6300 & geliş & var & standart \\
\hline 14 & $\begin{array}{l}15 \\
\text { y1l }\end{array}$ & $\mathrm{K}$ & ALL & $\begin{array}{l}\text { pre B hücreli } \\
\text { CD33 + CD13 + }\end{array}$ & 2000 & geliş & Tutulum yok & standart \\
\hline 15 & $\begin{array}{l}11 \\
\text { y1l } 1 \\
\text { ay }\end{array}$ & $E$ & $\begin{array}{l}\text { Relaps } \\
\text { ALL }\end{array}$ & $\begin{array}{l}\text { B hüicreli } \\
\text { CD13+33+ }\end{array}$ & 1800 & $\begin{array}{l}\text { nakil sonrası } \\
\text { relaps, } 1 \text {. ay }\end{array}$ & Tutulum yok & standart \\
\hline 16 & 7 ay & $E$ & ALL & $\begin{array}{l}\text { CALLA negatif } \\
\text { B hücreli }\end{array}$ & 202400 & 2.ayda & Tutulum yok & standart \\
\hline
\end{tabular}

E:Erkek, K: Kız, ALL: Akut Lenfoblastik Lösemi. 
Tablo 2: ALL hastalarına ait karyotipler

\begin{tabular}{|c|c|c|c|c|}
\hline $\begin{array}{l}\text { Hasta } \\
\text { No }\end{array}$ & Sitogenetik bulgular & $\begin{array}{l}\text { Sitogenetik } \\
\text { anormallik } \\
\text { hangi } \\
\text { safhada; } \\
\text { geliş/relaps }\end{array}$ & $\begin{array}{l}\text { relaps } \\
\text { (var/yok) }\end{array}$ & \begin{tabular}{|l|} 
Hayatta \\
kalım
\end{tabular} \\
\hline 1 & $\begin{array}{l}63- \\
65, \mathrm{XY},+\mathrm{X},+\mathrm{Y},+1,+1,+3,+5,+6,+6,+8,+9,+10,+11,+11,+13,+14,+15,+18,+19,+1 \\
9,+20,+20,+21,+22[17] / 46, \mathrm{X}[13]\end{array}$ & geliş & yok & Hayatta \\
\hline 2 & 46,XY,del(6)(q21),del(12)(p12),der(14)[10]/46,XY[10] & geliş & yok & Hayatta \\
\hline 3 & $\begin{array}{l}\text { 47,XX,del(9)(p22p24),+der(9)(p)add(9)(p),- } \\
20,+21(30] / 48, \operatorname{del}(9)(\mathrm{p} 22 \mathrm{p} 24),+\operatorname{der}(9)(\mathrm{p}) \operatorname{add}(9)(\mathrm{p}),- \\
20,+21,+\operatorname{mar} 1[10] / 46, \mathrm{XX}[10]\end{array}$ & geliş & yok & Hayatta \\
\hline 4 & $46, \mathrm{XY}, \mathrm{t}(7 ; 9)(\mathrm{p} 15 ; \mathrm{p} 22), \operatorname{del}(9)(\mathrm{p} 12 \mathrm{p} 24)[30]$ & geliş & yok & Hayatta \\
\hline 5 & $46, \mathrm{XY}, \mathrm{t}(12 ; 21)(\mathrm{p} 13 ; \mathrm{q} 21)[40] / 46, \mathrm{XY}[30]$ & geliş & yok & Hayatta \\
\hline 6 & $47, \mathrm{XY},-18,-20,-21,+\operatorname{mar} 1,+\operatorname{mar} 2,+\operatorname{mar} 3,+\operatorname{mar} 4[15] / 46, \mathrm{XY}[5]$ & geliş & yok & Hayatta \\
\hline 7 & $52-55, \mathrm{XY},+\mathrm{X},+4,+6,+10,+12,+14,+15,+20,+20,+21,+22[17] / 46, \mathrm{XY}[13]$ & geliş & yok & Hayatta \\
\hline 8 & $46, \mathrm{XY}, \mathrm{t}(4 ; 11)$ & geliş & yok & Hayatta \\
\hline 9 & $47, \mathrm{X},-\mathrm{X}, \operatorname{der}(16),+\operatorname{mar} 1,+\operatorname{mar} 2[4] / 46, \mathrm{XX}[46]$ & 7.hafta & yok & Hayatta \\
\hline 10 & $46, X Y, \operatorname{del}(7)(\mathrm{q} 31 \mathrm{q} 36)[9] / 46, \mathrm{XY}[31]$ & 48.hafta & yok & Hayatta \\
\hline 11 & $46, X Y, t(10 ; 14)(q ? ; q ?)[18] / 46, X Y[2]$ & geliş & yok & Hayatta \\
\hline 12 & $55, \mathrm{XY},+3,+6,+7,+8+12,+14,+15,+17,+21[2] / / 46, \mathrm{XY}[18]$ & 2.relapsta & var & Eks \\
\hline 13 & 46,XY,dup(1)(q31;q42),t(8;14)(q24;q32),+13[7]/46,XY[23] & geliş & var & Eks \\
\hline 14 & $51-59, \mathrm{XX},+1,+4,+5,+6,+8,+10,+10,+13,+14,+15,+15,+21,+21[10] / 46, \mathrm{XX}[20]$ & geliş & yok & Eks \\
\hline 15 & $45, \mathrm{XY},-7(5] / 47, \mathrm{XY},+19[20] / 46, \mathrm{XY}[5]$ & $\begin{array}{l}\text { nakil } \\
\text { sonras1 } \\
\text { relaps, 1. ay }\end{array}$ & var & Eks \\
\hline 16 & $46, \mathrm{XY}, \mathrm{t}(4 ; 11)(\mathrm{q} 21 ; \mathrm{q} 23)[43] / 46, \mathrm{XY}[16]$ & 2.ayda & yok & Hayatta \\
\hline
\end{tabular}

Del: Delesyon, der: Derivatif, mar: Marker kromozom, dup: Dublikasyon ,t:Translokasyon 
Tablo 3: AML hastalarının tanı anındaki özellikleri

\begin{tabular}{|c|c|c|c|c|}
\hline Hasta No & Tanı Yaşı & Cinsiyet & Tanı & $\begin{array}{l}\text { Geliş Beyaz Kürre } \\
\text { (/mm3) }\end{array}$ \\
\hline 1 & $\begin{array}{l}11 \text { yaş } 5 \\
\text { ay }\end{array}$ & $\mathrm{K}$ & AML & 20800 \\
\hline 2 & $7 \mathrm{yll}$ & $E$ & AML-M5 & 5500 \\
\hline 3 & 11 y1l 4 ay & $\mathrm{K}$ & AML & 6800 \\
\hline 4 & $2 \mathrm{yll}$ & $\mathrm{K}$ & AML-M7 & 4100 \\
\hline 5 & 2 ay & $\mathrm{K}$ & AML-M5 & 9200 \\
\hline 6 & 2.5 y1l & $E$ & $\begin{array}{l}\text { MDS/AM } \\
\mathrm{L}\end{array}$ & 12200 \\
\hline 7 & 3 y1l & $\mathrm{E}$ & AML-M4 & 165300 \\
\hline 8 & $17 \mathrm{y} 1 \mathrm{l}$ & $\mathrm{K}$ & AML-M2 & 132000 \\
\hline 9 & 7 y1l & $\mathrm{E}$ & AML & 8900 \\
\hline 10 & 11 y1l 2 ay & $E$ & AML-M5 & 3600 \\
\hline
\end{tabular}

E: Erkek, K: K1z, AML: Akut Myeloid Lösemi

Tablo 4: AML hastalarına ait karyotipler

\begin{tabular}{|c|c|c|c|c|}
\hline $\begin{array}{l}\text { Hasta } \\
\text { No }\end{array}$ & Sitogenetik bulgular & $\begin{array}{l}\text { Sitogenetik } \\
\text { anormallik hangi } \\
\text { safhada; geliş/relaps }\end{array}$ & $\begin{array}{l}\text { Relaps } \\
\text { (var/yok) }\end{array}$ & $\begin{array}{l}\text { Hayatta } \\
\text { kalım }\end{array}$ \\
\hline $\mathbf{1}$ & $47, \mathrm{XX},-7,+19,+21[2] / 45, \mathrm{XX},-7[12] / 46, \mathrm{XX}[6]$ & geliş & - & - \\
\hline 2 & $\begin{array}{l}\text { 46,XY,del(1)(q32q44), der(9), der(10)[9]/ 46,XY,der(5),- } \\
7,-9,+\operatorname{mar} 1,+\operatorname{mar} 2[9] / 46, X Y[2]\end{array}$ & 4.ayda & var & $\begin{array}{l}\text { Kemik iliği } \\
\text { nakli sonrası } \\
\text { eks }\end{array}$ \\
\hline 3 & $45, \mathrm{X},-\mathrm{X},-2, \operatorname{del}(8)(\mathrm{q} 13 \mathrm{q} 22),-21,+\operatorname{mar} 1,+\operatorname{mar} 2[20]$ & geliş & yok & Hayatta \\
\hline 4 & $\begin{array}{l}\text { 46,XX,der(6),- } \\
\text { 14,del(22)(q11.2),+mar1(1]/46,XX,der(2), der(6),- } \\
\text { 14,del(22)(q11.2),+mar1(3]/46,XX,der(6),-14,-14,- } \\
\text { 19,del(22)(q11.2),+mar1,+mar2,+mar3[14]/46,XX[12] }\end{array}$ & geliş & var & $\begin{array}{l}\text { Kemik iliği } \\
\text { nakli sonrası } \\
\text { eks }\end{array}$ \\
\hline 5 & $46, \mathrm{XX}, \mathrm{t}(1 ; 11)(\mathrm{p} 32 ; \mathrm{q} 23)(1] / 46, \mathrm{XX}(1]$ & geliş & - & Hayatta \\
\hline 6 & $\begin{array}{l}\text { 49,XY,der(1),+2, del(3)(p14p26),-14,-- } \\
22,+\operatorname{mar} 1,+\operatorname{mar} 2,+\operatorname{mar} 3,+\operatorname{mar} 4[7] / 46, \mathrm{XY}[43]\end{array}$ & geliş & var & $\begin{array}{l}\text { Kemik iliği } \\
\text { nakli sonrası } \\
\text { eks }\end{array}$ \\
\hline 7 & $47, \mathrm{XY},+8, \operatorname{del}(13)(\mathrm{q} 14 \mathrm{q} 22)[20]$ & 1.ayda & var & $\begin{array}{l}6 . \text { ayda } \\
\text { relaps } \\
\text { sonrasi eks } \\
\end{array}$ \\
\hline 8 & $\begin{array}{l}47, \mathrm{XY},+8[9] / 47, \mathrm{XX}, \operatorname{del}(4)(\mathrm{p} 16 \mathrm{p} 14),+8, \operatorname{der}(17),- \\
19,+\operatorname{mar} 1[10] / 46, \mathrm{XY}[1]\end{array}$ & Relaps anında & var & $\begin{array}{l}\text { 3.ayda } \\
\text { sepsis } \\
\text { sebebi ile } \\
\text { eks }\end{array}$ \\
\hline 9 & $\begin{array}{l}52-83, \mathrm{XY},+\mathrm{X},+\mathrm{X},+\mathrm{Y},+\mathrm{Y},-2,+3,-4,+5,+6,-7,+9,+11,- \\
12,+13,+13,+14,+16,+17,+17,+18,+19,+19,+20,+20,+2 \\
1,+21,+22,+22,+\operatorname{mar} 1,+\operatorname{mar} 2,+\operatorname{mar} 3,+\operatorname{mar} 4,+\operatorname{mar} 5,+\mathrm{ma} \\
\mathrm{r} 6,+\operatorname{mar} 7,+\operatorname{mar} 8,+\operatorname{mar} 9[8] / 46, \mathrm{XY}[12]\end{array}$ & geliş & yok & Hayatta \\
\hline 10 & $47, \mathrm{XY},+15, \operatorname{der}(20)[20]$ & geliş & yok & Hayatta \\
\hline
\end{tabular}

Del: Delesyon, der: Derivatif, mar: Marker kromozom, dup: Dublikasyon ,t:Translokasyon 


\section{REFERANSLAR}

1- Annesley CE, Brown P. Novel agents for the treatment of childhood acute leukemia. Ther Adv Hematol. 2015; 6:61-79.

2- Braoudaki M, Tzortzatou-Stathopoulou F. Clinical cytogenetics in pediatric acute leukemia: an update. Clin Lymphoma Myeloma Leuk. 2012; 12: 230-7.

3- Seth R, Singh A. Leukemias in Children. Indian J Pediatr. 2015; 82: 817-24.

4- Woo JS, Alberti MO, Tirado CA. Childhood Bacute lymphoblastic leukemia: a genetic update. Exp Hematol Oncol. 2014; 3:16.

5- Inaba H, Greaves M, Mullighan CG. Acute lymphoblastic leukaemia. Lancet. 2013; 381:1943-55.

6- Al-Mulla NA, Chandra P, Khattab M, et al. Childhood acute lymphoblastic leukemia in the Middle East and neighboring countries: a prospective multiinstitutional international collaborative study (CALLME1) by the Middle East Childhood Cancer Alliance (MECCA). Pediatr Blood Cancer. 2014; 61:1403-10.

7- Manola KN. Cytogenetics of pediatric acute myeloid leukemia. Eur J Haematol. 2009; 83: 391-405.
8- Haffer LG, McGowan-Jordan J, Schmid M. ISCN: An International Systemfor Human Cytogenetic Nomenclature. Karger Publisher, 2013

9- Paulsson K, Lilljebjörn H, Biloglav A, et al. The genomic landscape of high hyperdiploid childhood acute lymphoblastic leukemia. Nat Genet. 2015; 47: 6726.

10- Kato M, Imamura T, Manabe A, et al. Prognostic impact of gained chromosomes in high hyperdiploid childhood acute lymphoblasticleukaemia: a collaborative retrospective study of the Tokyo Children's Cancer Study Group and Japan Association of Childhood Leukaemia Study. Br J Haematol. 2014; 166: 295-8.

11- Aksu Uzunhan T, Karakaş Z. Çocukluk Çağı Akut Lenfoblastik Lösemisi.Çocuk Dergisi. 2012; 12: 6-15.

12- Moorman AV. The clinical relevance of chromosomal and genomic abnormalities in B-cell precursor acute lymphoblastic leukaemia. Blood Rev. 2012; 26: 123-35.

13- Harrison CJ. Targeting signaling pathways in acute lymphoblastic leukemia: new insights. Hematology Am Soc Hematol Educ Program. 2013; 2013: 118-25.

14- Atlas of Genetics and Cytogenetics in Oncology and Haematology. http://atlasgeneticsoncology.org/ 201 